\title{
A Cytoprotective and Degradable Metal-Polyphenol Nanoshell for Single-Cell Encapsulation
}

\author{
Ji Hun Park, ${ }^{[a, e]}$ Kyunghwan Kim, ${ }^{[b, e]}$ Juno Lee,${ }^{[a]}$ Ji Yu Choi, ${ }^{[a]}$ Daewha Hong ${ }^{[a]}$ Sung Ho Yang, ${ }^{[c]}$ Frank \\ Caruso, ${ }^{*[d]}$ Younghoon Lee, ${ }^{*[b]}$ and Insung S. Choi*[a]
}

\begin{abstract}
Single-cell encapsulation promises the cytoprotection of the encased cells against lethal stressors, reminiscent of sporulation process in Nature. However, the development of a cytocompatible method for chemically mimicking the germination process (i.e., shell degradation ondemand) has been elusive, despite the shell degradation being pivotal for the practical use of functional cells as well as for single cell-based biology. We report that an artificial shell, composed of tannic acid (TA) and Fe(III), on individual Saccharomyces cerevisiae controllably degrades on-demand, while protecting the yeast from multiple external aggressors, including $U V$ $C$ irradiation, lytic enzymes, and silver nanoparticles. Cell division is suppressed by the TA-Fe(III) shell, but restored fully upon shell degradation. The formation of TA-Fe(III) shell would provide a versatile tool for achieving the chemical version of "sporulation and germination".
\end{abstract}

Some bacteria, such as bacillus, clostridia, and sporosarcina, have the environment-responsive, mutually orchestrated biological processes, namely sporulation and germination. ${ }^{1}$ Sporulation is a cellular differentiation process to counteract hostile external stressors, such as malnutrition, dehydration, heat, and radiation, which shuts down cellular metabolism and constructs a robust proteinaceous shell. ${ }^{1 a}$ The shell precludes physical access of foreign aggressors to the interior and detoxifies reactive toxic chemicals. The protective shell, on the other hand, degrades when the spore's inner membrane senses a hospitable environment for reproduction, which is called germination. ${ }^{1 b}$ The cellular-level adaptation to environmental changes found in nature has inspired researchers to mimic the sporulation process structurally (i.e., to chemically form an ultrathin and robust artificial shell on the nonspore forming cell) for increasing the in vitro stability of cells, because most living cells are extremely vulnerable to laboratory or practical applications. $^{2}$

[a] J. H. Park, J. Lee, J. Y. Choi, D. Hong, Prof. I. S. Choi Center for Cell-Encapsulation Research and Molecular-Level Interface Research Center

Department of Chemistry, KAIST

Daejeon 305-701 (Korea)

E-mail: ischoi@kaist.ac.kr

[b] K. Kim, Prof. Y. Lee

Department of Chemistry

KAIST

Daejeon 305-701 (Korea)

[c] Prof. S. H. Yang

Department of Chemistry Education

Korea National University of Education

Chungbuk 363-791 (Korea)

[d] Prof. F. Caruso

Department of Chemical and Biomolecular Engineering

The University of Melbourne

Parkville, Victoria 3010 (Australia)

[e] These authors contributed equally to this work.

Supporting information for this article is given via a link at the end of the document.((Please delete this text if not appropriate))
Previous cell-encapsulation studies, mimicking the sporulation process, show that a durable artificial shell can lead to enhanced cellular tolerance against external stressors. ${ }^{2 b}$ The nanoshells of silica, ${ }^{3}$ silica-titania, ${ }^{4}$ graphene, ${ }^{5}$ or polydopamine ${ }^{6}$ were formed on microbial and mammalian cells, and the enhanced resistances to physicochemical stresses, malnutrition, enzymatic attack, or heat were reported However, the development of a cytocompatible method for chemically mimicking the germination process (i.e., shell degradation on-demand) has been elusive, although the programmed breaking-up of the cytoprotective shell is pivotal for the practical use of cells in sensors, drug delivery systems, cell therapy, or regenerative medicine. ${ }^{7}$ The tough shell is often a physical barrier to the biological actions of the encapsulated cells inside, particularly if the shell does not respond to environmental changes. Therefore, the formation of a cytoprotective shell that degrades on-demand is highly desired for field-deployability of cell-loaded materials and devices. ${ }^{8}$ The bottleneck to the development of such a dually-functional shell is the incompatibility of the chemical conditions required to degrade the shell encasing living cells. The conventional strategies for the disintegration of physicochemically durable materials generally require noxious chemicals and harsh conditions, which lead to cell death. ${ }^{9}$

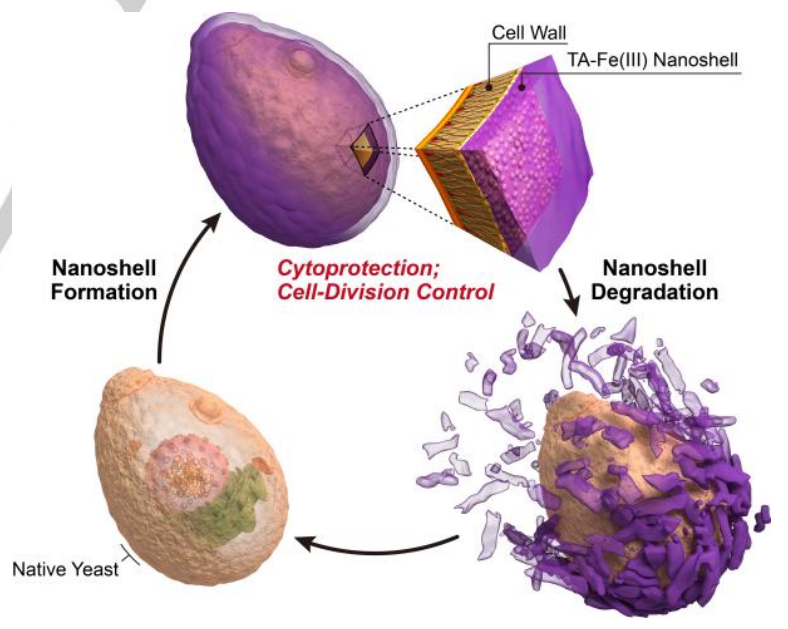

Figure 1. Schematic representation for controlled formation and degradation of the TA-Fe(III) shell on individual S. cerevisiae.

Metal-organic films, based on non-covalent coordination complexes, are structurally rigid, but could respond to external stimuli and be degraded under cytocompatible conditions. In the current study, we found that a metal-organic film, composed of a natural polyphenol (tannic acid; TA) and $\mathrm{Fe}(\mathrm{III}),{ }^{10}$ was structurally rigid, but could respond to external stimuli and be degraded under cytocompatible conditions, fulfilling the criteria for dually functional shells. The substrate-independant coating, using coordination complexes of TA and $\mathrm{Fe}(\mathrm{III})$ ions, was fast (in seconds) and highly biocompatible, forming a TA-Fe(III) shell on individual yeast (Figure 1; see the Experimental Section for the detailed procedure). Briefly, the TA$\mathrm{Fe}(\mathrm{III})$ shell was formed simply by adding aqueous solutions of TA and $\mathrm{FeCl}_{3} \cdot 6 \mathrm{H}_{2} \mathrm{O}$ to the aqueous yeast suspension and incubating the 
mixture for $10 \mathrm{sec}$. The process was repeated two or four times, leading to the formation of $[\mathrm{TA}-\mathrm{Fe}(\mathrm{III})]_{2}$ or $[\mathrm{TA}-\mathrm{Fe}(\mathrm{III})]_{4}$ shell, respectively. For the characterizations, yeast@[TA-Fe(III) $]_{4}$ was used. The fluorescein diacetate (FDA) assay, accessing the esterase activity in the metabolically intact cells, indicated that most of yeast@[TA-Fe(III) $]_{4}$ were viable after shell formation. Mitochondrial activity was also measured by a resazurin assay, and the fluorescent intensity of yeast@[TA-Fe(III) $]_{4}$ reached that of native yeast $(98 \pm 2.5 \%)$, confirming the unprecedented cytocompatibility of the encapsulation processes (see the Supporting Information Figure S1). ${ }^{11}$ Successful shell formation was supported by the Raman spectrum of yeast@[TA-
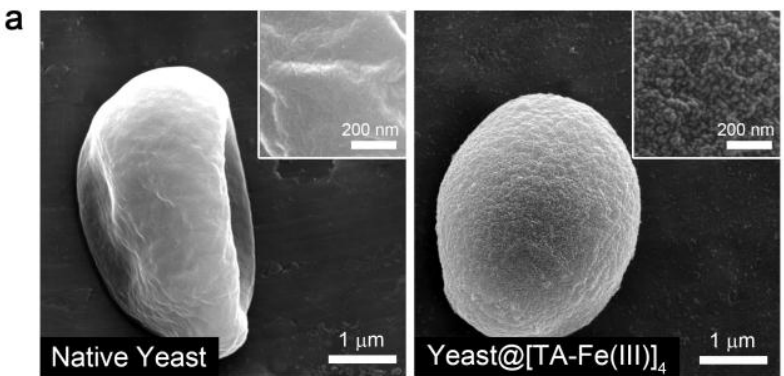

b
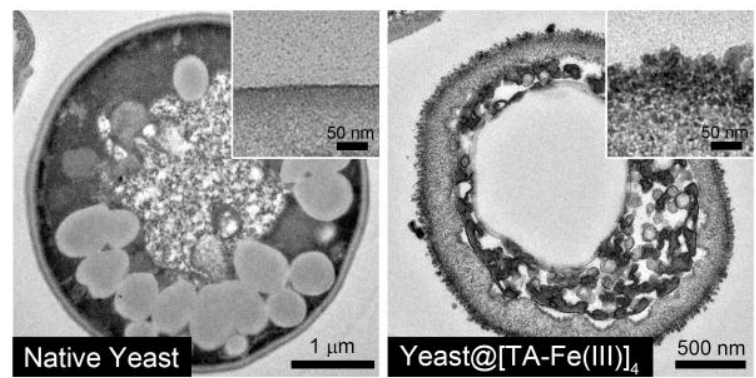

C
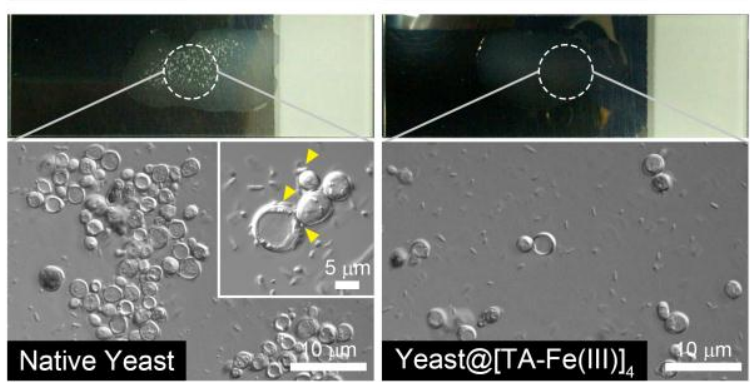

d
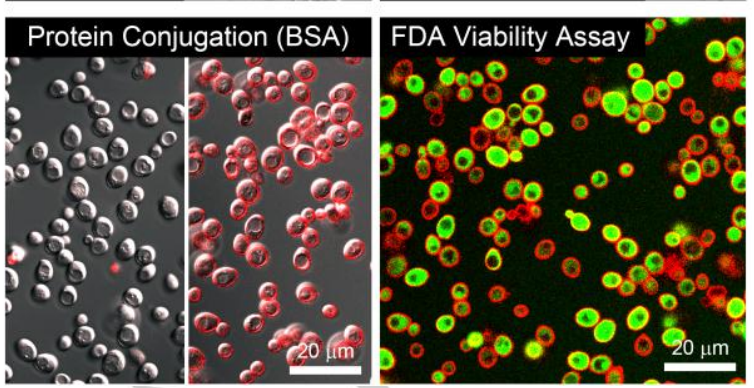

Figure 2. Characterizations of native yeast and yeast@[TA-Fe(III)]4. a,b) FESEM and TEM micrographs of (left panel) native yeast and (right panel) yeast@[TA-Fe(III)]4. c) Inhibition of E. coli-induced yeast agglutination: (left panel) native yeast and (right panel) yeast@ [TA-Fe(III)]4. The magnified optical images (bottom) were taken by CLSM. The yellow arrowhead in the inset indicates $E$. coli in the magnified CLSM image. d) (left panel) CLSM images of (left) native yeast and (right) yeast@ $[\mathrm{TA}-\mathrm{Fe}(\mathrm{III})]_{4}$ after treatment of BSA-Alexa Fluor $^{\circledR}$ 647. (right panel) CLSM image of yeast@[TA-Fe(III)] $]_{4}$ treated with both FDA (for viability assay) and BSA-Alexa Fluor ${ }^{\circledR} 647$.
$\mathrm{Fe}(\mathrm{III})]_{4}$, which showed intense bands at 1354 and $1482 \mathrm{~cm}^{-1}$ (the C-C ring vibration along with $\mathrm{C}-\mathrm{H}$ bending in TA) (see the Supporting Information Figure S2). ${ }^{12}$ The SEM and TEM images also confirmed the formation of a TA-Fe(III) shell on yeast (Figure 2a,b). The highmagnification SEM micrograph showed that individual yeast was coated fully with a TA-Fe(III) layer (Figure 2a). The TA-Fe(III) shell was also clearly observed in the TEM micrograph of the microtomed yeast@[TA-Fe(III)]4, and its averaged thickness was ca. 40 nm (Figure $2 b)$. The averaged thickness corresponded well with our previous results that the shell thickness increased by $10 \mathrm{~nm}$, when a TA-Fe(III) layer was sequentially deposited on the former layer of TA-Fe(III). ${ }^{10 \mathrm{~d}}$ Microelectrophoresis measurements indicated that the zeta potential was $-9 \mathrm{mV}$ for native yeast ${ }^{13}$ and, after formation of the [TA-Fe(III) $]_{4}$ shell, $-18 \mathrm{mV}$ (data not shown). The negative charge of the TA-Fe(III) shell prevented the undesired self-aggregation of yeast@[TA-Fe(III) $]_{4}$ and also acted as a physical barrier to inhibit agglutination with $E$. coli (Figure 2c).${ }^{14}$ To visualize the shell, we immobilized a fluorophoreconjugated protein (BSA-Alexa Fluor ${ }^{\circledR}$ 647) onto yeast@ $[$ TA-Fe(III)]4, and subsequently added FDA (Figure 2d). The core-shell structure was observed for viable cells, also indicating the formation of a uniform TA-Fe(III) shell (BSA-Alexa Fluor ${ }^{\circledR} 488$ was also immobilized onto yeast@[TA-Fe(III)]4; see the Supporting Information Figure S3).

The TA-Fe(III) shell suppressed cell division, in part reminiscent of sporulation, in plate cultures. We serially diluted an aqueous solution of native or encapsulated yeast $\left(\mathrm{OD}_{600}=2\right)$, spread the 2000 -fold diluted solution on a yeast extract-peptone-adenine-dextrose (YPAD) agar plate, and cultured the yeast for $48 \mathrm{~h}$. Colony-forming unit (CFU) was calculated by multiplying the dilution factor and the colony number. Yeast@[TA-Fe(III) $]_{2}$ was used for comparison (see the Supporting Information Figure S4 for the TEM micrograph of microtomed yeast $\left.@[\mathrm{TA}-\mathrm{Fe}(\mathrm{III})]_{2}\right)$. The logarithmic value of $\mathrm{CFU}$ per $\mathrm{mL}(\log \mathrm{CFU} / \mathrm{mL})$ was $7.12 \pm 0.02$ for native yeast or $4.47 \pm 0.02$ for yeast@[TA-Fe(III) $]_{4}$ (Figure 3a; also see the Supporting Information Table S1). The data showed that yeast@TA-Fe(III) was inactive or significantly less active statistically in cell division than native yeast by at least two-and-a-half orders of magnitude (> 450-fold). The difference in $\log \mathrm{CFU} / \mathrm{mL}$ was significant: only 2 colonies were observed on average for yeast@[TA-Fe(III)]4, while about 1000 colonies were formed for native yeast. As expected, the $\log \mathrm{CFU} / \mathrm{mL}$ value was varied by the thickness of the TA-Fe(III) shell: $5.71 \pm 0.02$ for yeast@[TA-Fe(III) $]_{2}$. The shell was, therefore, an effective suppressor for cell division, presumably by acting as a physical barrier that prevented the cell-in-shell from contacting solid-state nutrients on the culture plate. Another explanation would be the stiffness of the TA$\mathrm{Fe}(\mathrm{III})$ shell. A previous report showed that the matrix stiffness affects cell cycle progression. ${ }^{15}$ On the other hand, the TA-Fe(III) shell was degraded under mild conditions (e.g., by adding $\mathrm{HCl}$ ). ${ }^{10 \mathrm{~d}}$ The solution color of yeast@[TA-Fe(III) $]_{4}$ turned into white from violet when $\mathrm{HCl}$ was added, indicative of shell degradation (see the Supporting Information Figure S5). After 90-min treatment with $20 \mathrm{mM} \mathrm{HCl}$, the $\log \mathrm{CFU} / \mathrm{mL}$ value for yeast @ [TA-Fe(III)]4 was dramatically increased to $6.91 \pm 0.02$, which was similar to that for native yeast $(7.01 \pm 0.00)$. The value for native yeast did not noticeably change after $\mathrm{HCl}$ treatment, confirming the cytocompatible, mild conditions for shell degradation. The increase in $\log \mathrm{CFU} / \mathrm{mL}$ was confirmed to be caused by shell degradation: when we used the lower $\mathrm{HCl}$ concentration (5 $\mathrm{mM}),[\mathrm{TA}-\mathrm{Fe}(\mathrm{III})]_{2}$ dissolved more easily and faster than [TA-Fe(III) $]_{4}$, leading to the higher $\log \mathrm{CFU} / \mathrm{mL}$ value in a given time. 
a

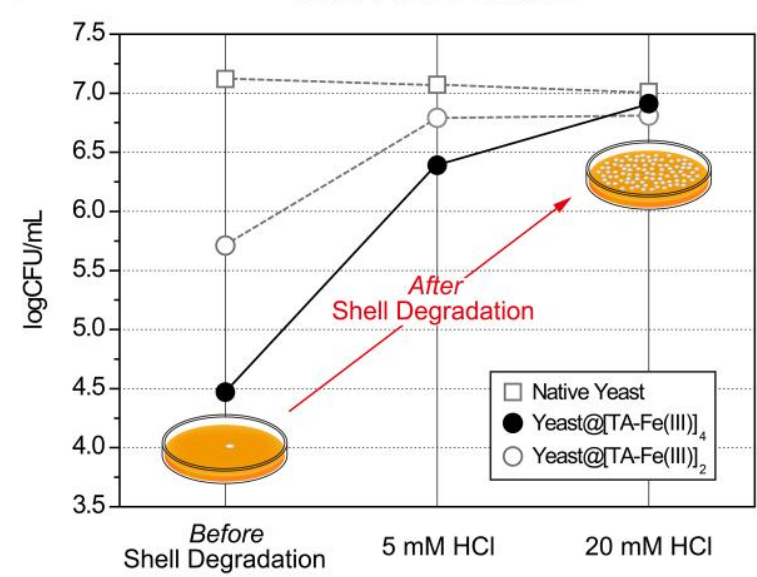

b

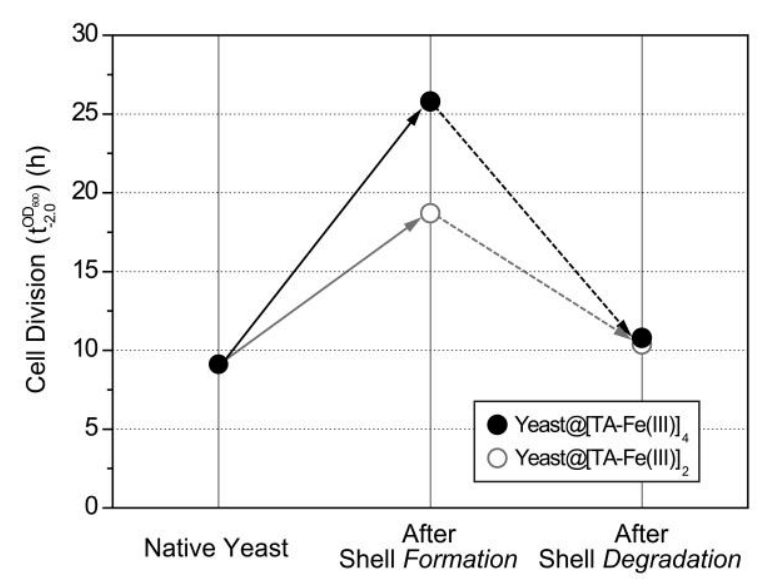

Figure 3. Control of cell division by shell formation and degradation. a) $\log \mathrm{CFU} / \mathrm{mL}$ values and b) $t_{-2.0}^{\mathrm{O}_{\mathrm{o}}}$ values of yeast@TA-Fe(III) before and after 90 -min treatment of 20 $\mathrm{mM} \mathrm{HCl}$ with native yeast as a comparison.

The on-demand degradation for controlled cell division was also investigated in a solution-phase culture. The $t_{-20}^{O_{00}}$ value (defined as the time when $\operatorname{lnOD}_{600}$ reaches -2$)^{16}$ increased with the shell thickness, indicating a retardation effect: compared with native yeast, the $t_{-2.0}^{\mathrm{oO}_{20}}$ value increased up to $18.7 \pm 3.5 \mathrm{~h}$ for [TA-Fe(III) $]_{2}$ or $25.8 \pm 3.1 \mathrm{~h}$ for [TA-Fe(III) $]_{4}$ (Figure 3b). It is noted that the encapsulated cells showed an unperturbed growth rate $(\mu)\left(0.525 \pm 0.032 \mathrm{~h}^{-1}\right.$ for native yeast; $0.594 \pm 0.059 \mathrm{~h}^{-1}$ for yeast@[TA-Fe(III) $]_{2} ; \quad 0.569 \pm 0.072 \mathrm{~h}^{-1}$ for yeast@[TA-Fe(III) $\left.]_{4}\right)$, even though TA was considered as a restrictive agent for the respiratory chain, possibly leading to slower growth rates and less fermentation products. ${ }^{17}$ The result additionally confirmed that the combination of TA and Fe(III) (and the shell-forming conditions)

a

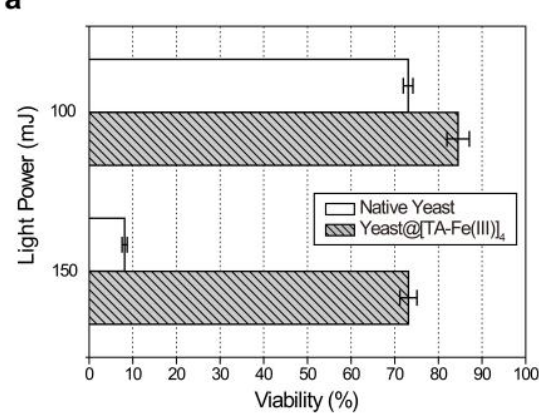

b

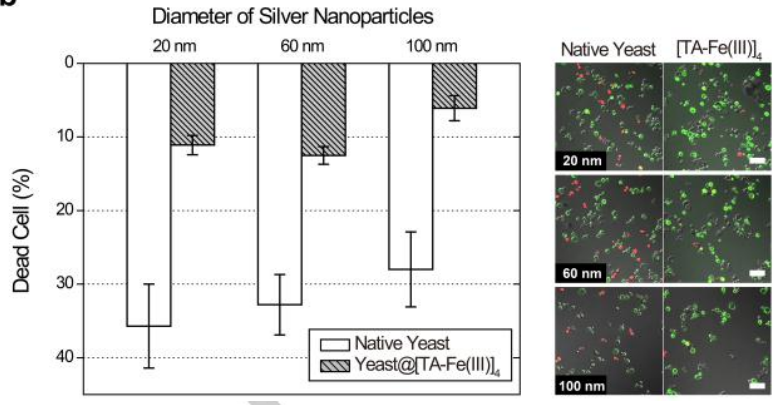

Figure 4. Enhanced tolerance of yeast@TA-Fe(III) against external stressors. a UV-C tolerance of yeast@[TA-Fe(III)]4. b) Cytoprotection ability of the TA$\mathrm{Fe}(\mathrm{III})$ nanoshell against silver nanoparticles with different sizes in diameter. Yeast@[TA-Fe(III) $]_{4}$ was treated with FDA and propidium iodide (PI) for live/dead staining. All scale bars are $20 \mu \mathrm{m}$. did not alter the metabolic activities. On the other hand, the $\mathrm{HCl}$ treatment $(20 \mathrm{mM}$; 30 or $90 \mathrm{~min}$ ) almost restored the division ability of both yeast@[TA-Fe(III)]2 and yeast@[TA-Fe(III)]4 (for 30-min $\mathrm{HCl}$ treatment, see the Supporting Information Figure S6). The processes of shell formation and degradation could be repeated (see the Supporting Information Figure S7). Taken together, both plate- and solution-based data clearly demonstrate the reversibility of the TA-Fe(III) shell.

In addition to the cytocompatible degradability of the TA-Fe(III) shell, the shell acted as a protective layer against multiple stressors. For example, DNA and proteins in living organisms are damaged by UV-C ( $\lambda$ : 100 to $280 \mathrm{~nm}$ ); ${ }^{18}$ the UV-C radiation could be screened by the TA$\mathrm{Fe}$ (III) shell, because the TA-Fe(III) film absorbs the UV light, especially in the middle-UV region $(200-300 \mathrm{~nm}){ }^{10 \mathrm{~d}}$ Figure 4a shows the protective ability of the shell against UV-C irradiation. When UV$\mathrm{C}$ light $(254 \mathrm{~nm})$ was irradiated with $150 \mathrm{~mJ}$ of light power, $92.0 \pm 0.6 \%$ of native yeast died, but $73.1 \pm 1.9 \%$ of yeast@ $[\mathrm{TA}-\mathrm{Fe}(\mathrm{III})]_{4}$ were kept viable, indicating a 9-fold enhancement in the UV-C tolerance. The shell also resisted the lethal lytic enzyme. After 3-h incubation of native yeast with lyticase, we observed a $79.0 \pm 0.2 \%$-drop in the $\mathrm{OD}_{600}$ value. In comparison, $96.6 \pm 0.9 \%$ of the initial $\mathrm{OD}_{600}$ value was maintained for yeast@[TA-Fe(III)]4. Furthermore, the TA-Fe(III) nanoshell also showed the protection ability against silver nanoparticles that ruptured the cell walls by physical contact (Figure 4b). ${ }^{19}$

In summary, we have reported a coordination complex-mediated method for dynamically encapsulating individual yeast cells with tannic acid (TA) and Fe(III). Besides the simple, substrate-independent fabrication approach, the TA-Fe(III) shell has several important characteristics in the chemical manipulation of cell-material interfaces: (1) high cytocompatibility: the growth curves, along with the fluorescein diacetate and resazurin assays, confirmed that the materials and processes for the shell formation had no or negligible effect on the metabolic activities and viability. The high cytocompatibility would make it possible to apply this method to structurally labile mammalian cells (for HeLa cells, see the Supporting Information Figure S8); ${ }^{3 \mathrm{c}}$ (2) facile degradability: the shell controlled the cell division by its formation and degradation. The degradation on-demand of the shell is particularly important for cell-based devices that require both longterm preservation of cells under ambient conditions and controlled exposure of the cells, when needed, on the spot; and (3) 
cytoprotectability: the demonstrated examples included the enhanced protection of yeast@TA-Fe(III) against binding of E. coli, UV-C irradiation, lyticase, and silver nanoparticles. The cytoprotection against other harmful aggressors would be achieved by postmodification of the shell. In addition, the TA-Fe(III) shell also could be functionalized with either biologically active molecules or functional nanomaterials, which are advantageous for interfacing yeast@TA$\mathrm{Fe}(\mathrm{III})$ with conventional microfabrication processes in cell-based sensors and devices (for pattern generation and magnetic functionalization, see the Supporting Information Figure S9,10). ${ }^{2 c, 20}$

Recent interest in cell coating/encapsulation focuses on the formation of cell-in-nano-nutshell structures ("artificial spores"), inspired by bacterial endospores, the shell of which is mechanically rigid and protective but degrades when needed. ${ }^{21}$ The method demonstrated herein is highly cytocompatible and generates a dually functional (protective and degradable) nanoshell, which is likely to advance the chemical tools for single-cell manipulation.

\section{Experimental Section}

Encapsulation of Individual S. cerevisiae with TA-Fe(III) Shells. A single colony of S. cerevisiae (Baker's yeast) was picked from a YPAD agar plate and cultured in the YPAD broth liquid media with continuous shaking at $30^{\circ} \mathrm{C}$ for 60 $\mathrm{h}$. The yeast cells were washed with deionized (DI) water three times and dispersed in DI water. The $5 \mu \mathrm{L}$ aqueous solution of TA $\left(40 \mathrm{mg} \cdot \mathrm{mL}^{-1}\right)$ and the 5 $\mu \mathrm{L}$ aqueous solution of $\mathrm{FeCl}_{3} \cdot 6 \mathrm{H}_{2} \mathrm{O}\left(10 \mathrm{mg} \cdot \mathrm{mL}^{-1}\right)$ were added sequentially to the aqueous suspension of yeast cells $(490 \mu \mathrm{L})$ with 10 -sec vigorous mixing between the additions. After addition of the $\mathrm{FeCl}_{3} \cdot 6 \mathrm{H}_{2} \mathrm{O}$ solution, the resulting suspension was mixed vigorously for $10 \mathrm{sec}$, and $0.5 \mathrm{~mL}$ of $3-(N-$ morpholino)propanesulfonic acid (MOPS) buffer (20 mM, pH 7.4) was added to the yeast@TA-Fe(III) suspension for the stabilization of the pH, resulting in the formation of stable TA-Fe(III) shell. Yeast@TA-Fe(III) was washed with DI water three times to remove any residual $\mathrm{TA}$ and $\mathrm{FeCl}_{3}$. The coating process from addition of $\mathrm{TA}$ and $\mathrm{FeCl}_{3}$ to washing with DI water was repeated two or four times.

\section{Acknowledgements}

This work was supported by the Basic Science Research Program through the National Research Foundation of Korea (NRF) funded by the Ministry of Science, ICT \& Future Planning (MSIP) (2012R1A3A2026403 to I.S.C.; 2011-0020322 and 2012M3A6A8055678 to Y.L.) and the Australian Research Council under the Australian Laureate Fellowship Scheme (FL120100030 to F.C.). M.S.J. at the KBSI (Chuncheon) is thanked for technical assistance with the preparation of microtome-sliced samples.

Keywords: artificial spores $\cdot$ tannic acid $\bullet$ encapsulation • nanostructures $\cdot$ organic-inorganic hybrid composites

[1] a) P. T. McKenney, A. Driks, P. Eichenberger, Nat. Rev. Microbiol. 2012, 11 , 33-44; b) A. O. Henriques, C. P. Moran, Jr. Annu. Rev. Microbiol. 2007, 61,
555-588; c) S. Ghosh, B. Setlow, P. G. Wahome, A. E. Cowan, M. Plomp, A. J. Malkin, P. Setlow, J. Bacteriol. 2008, 190, 6741-6748.

[2] a) D. Hong, M. Park, S. H. Yang, J. Lee, Y.-G. Kim, I. S. Choi, Trend Biotechnol. 2013, 31, 442-447; b) S. H. Yang, D. Hong, J. Lee, E. H. Ko, I. S Choi, Small 2013, 9, 178-186; c) R. F. Fakhrullin, A. I. Zamaleeva, R. T. Minullina, S. A. Konnova, V. N. Paunov, Chem. Soc. Rev. 2012, 41, 41894206; d) R. F. Fakhrullin, Y. M. Lvov, ACS Nano 2012, 6, 4557-4564.

[3] a) S. H. Yang, K.-B. Lee, B. Kong., J.-H. Kim, H.-S. Kim, I. S. Choi, Angew. Chem. Int. Ed. 2009, 48, 9160-9163; b) W. Xiong, Z. Yang, H. Zhai, G. Wang, X. Xu, W. Ma. R. Tang, Chem. Commun. 2013, 49, 7525-7527; c) J. Lee, J. Choi, J. H. Park, M.-H. Kim, D. Hong, H. Cho, S. H. Yang, I. S. Choi, Angew. Chem. Int. Ed. 2014, DOI: 10.1002/anie.201402280.

[4] E. H. Ko, Y. Yoon, J. H. Park, S. H. Yang, D. Hong, K.-B. Lee, H. K. Shon, T. G. Lee, I. S. Choi, Angew. Chem. Int. Ed. 2013, 52, 12279-12282.

[5] R. Kempaiah, S. Salgado, W. L. Chung, V. Maheshwari, Chem. Commun. 2011, 47, 11480-11482.

[6] S. H. Yang, S. M. Kang, K.-B. Lee, T. D. Chung, H. Lee, I. S. Choi, J. Am Chem. Soc. 2011, 133, 2795-2797.

[7] a) M. A. Fischbach, J. A. Bluestone, W. A. Lim, Sci. Transl. Med. 2013, 5, 179ps7; b) T. M. S. Chang, Nat. Rev. Drug Discov. 2005, 4, 221-235.

[8] E. Michelini, L. Cevenini, M. M. Calabretta, S. Spinozzi, C. Camborata, A Roda, Anal. Bioanal. Chem. 2013, 405, 6155-6163.

[9] I. Drachuk, M. K. Gupta, V. V. Tsukruk, Adv. Funct. Mater. 2013, 23, 44374453.

[10] a) J. Guo, Y. Ping, H. Ejima, K. Alt, M. Meissner, J. J. Richardson, Y. Yan, K. Peter, D. v. Elverfeldt, C. E. Hagemeyer, F. Caruso, Angew. Chem. Int. Ed 2014, 53, 5546-5551; b) M. A. Rahim, H. Ejima, K. L. Cho, K. Kempe, M Müllner, J. P. Best, F. Caruso, Chem. Mater. 2014, 26, 1645-1653; c) S. Kim, D. S. Kim, S. M. Kang, Chem. Asian J. 2014, 9, 63-66; d) H. Ejima, J. J. Richardson, K. Liang, J. P. Best, M. P. v. Koeverden, G. K. Such, J. Cui, F. Caruso, Science 2013, 341, 154-157.

[11] V. Kozlovskaya, S. Harbaugh, I. Drachuk, O. Shchepelina, N. KelleyLoughnane, M. Stone, V. V. Tsukruk, Soft Matter 2011, 7, 2364-2372.

[12] G. Piantanida, E. Menart, M. Bicchieri, M. Strlič, J. Raman Spectrosc. 2013, 44, 1299-1305

[13] W. R. Bowen, R. W. Lovitt, C. J. Wright, J. Colloid Interface Sci. 2001, 237 , 54-61.

[14] a) M. N. Liang, S. P. Smith, S. J. Metallo, I. S. Choi, M. Prentiss, G. M. Whitesides, Proc. Natl. Acad. Sci. USA 2000, 97, 13092-13096; b) Y. Eshdat, V. Speth, K. Jann, Infec. Immun. 1981, 34, 980-986.

[15] T. Aikawa, T. Konno, K. Ishihara, Soft Matter 2013, 9, 4628-4634

[16] a) J. Lee, S. H. Yang, S.-P. Hong, D. Hong, H. Lee, H.-Y. Lee, Y.-G. Kim., I S. Choi, Macromol. Rapid Commun. 2013, 34, 1351-1356; b) W. A. Kratz, J. Myers, Am. J. Bot. 1955, 42, 282-287.

[17] T. Wauters, D. Iserentant, H. Verachtert, Can. J. Microbiol. 2001, 47, 290-293.

[18] T. A. Slieman, W. L. Nicholson, Appl. Environ. Microbiol. 2001, 67, 12741279.

[19] a) L. Liu, J. Yang, J. Xie, Z. Luo, J. Jiang, Y. Y. Yang, S. Liu, Nanoscale 2013 , 5, 3834-3840; b) M. Rai, A. Yadav, A. Gade, Biotechnol. Adv. 2009, 27, 76-83.

[20] I. Safarik, K. Pospiskova, K. Horska, M. Safarikova, Soft Matter 2012, 8 , 5407-5413.

[21] J. H. Park, S. H. Yang, J. Lee, E. H. Ko, D. Hong, I. S. Choi, Adv. Mater. 2014 26, 2001-2010.

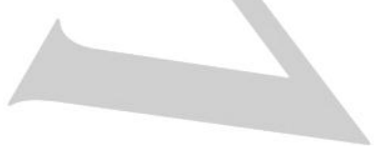




\section{COMMUNICATION}

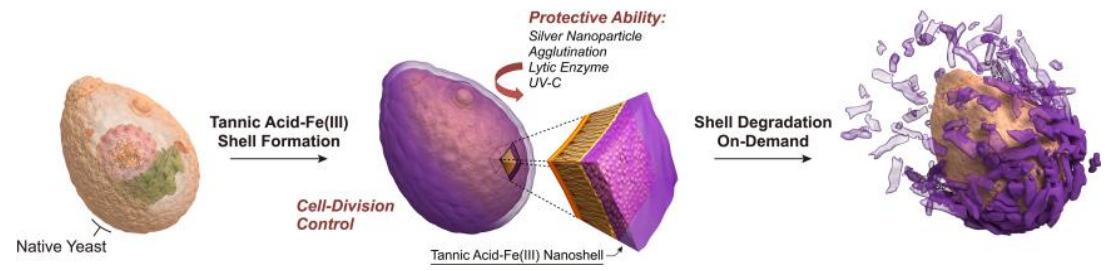

A cytoprotective tannic acid-Fe(III) nanoshell was formed on individual yeast cells, and the cell division was controlled reversibly by formation and degradation of the nanoshell.
Ji Hun Park, Kyunghwan Kim, Juno Lee, Ji Yu Choi, Daewha Hong, Sung Ho Yang, Frank Caruso, * Younghoon Lee, * and Insung S. Choi*

Page No. - Page No.

A Cytoprotective and Degradable Metal-Polyphenol Nanoshell for Single-Cell Encapsulation 